\title{
Lithography of Self-assembled Semiconductor Quantum Dots on Templates Fabricated from Mixed Langmuir-Blodgett Films
}

\author{
Satoshi Watanabe* , Naoya Tamura and Mutsuyoshi Matsumoto \\ Department of Materials Science and Technology, Tokyo University of Science (Yamazaki 2641, Noda, Chiba 278-8510, JAPAN)
}

\begin{abstract}
In this paper, we discuss a useful technique to fabricate patterned single layers consisting of quantum dots on two-dimensional templates fabricated from phase-separated mixed Langmuir-Blodgett (LB) films. The phase-separated structures are governed by two competing interactions-line tension and dipole-dipole interaction-and are tunable by adjusting the intermolecular interactions between the filmforming molecules and the fabrication conditions. The templates can be fabricated from mixed LB films containing silane-coupling agents, which form covalent bonds with Si wafers. The CdS- or CdSe/ZnSnanoparticles were immobilized on the templates using a chemisorption technique. The samples were analyzed using ultraviolet-visible absorption spectroscopy, emission spectroscopy, atomic force microscopy, scanning electron microscopy, and fluorescence microscopy. The diameters of the CdS-NPs and CdSe/ZnS were estimated to be about 2.6 and $4.5 \mathrm{~nm}$, respectively, using the Brus equation. We successfully obtained a patterned single layer consisting of quantum dots on the templates. The density of the immobilized-CdSe/ ZnS-NPs on these templates can be controlled through variations in the concentration of the aqueous dispersion of $\mathrm{CdSe} / \mathrm{ZnS}-\mathrm{NPs}$. Fluorescence observations indicate that the immobilized-CdSe/ZnS-NPs on the templates serve as light-emitting devices. These results indicate that patterned quantum dots can be formed only through self-assembly processes.
\end{abstract}

Key words: Phase separation, LB film, semiconductor quantum dot, fluorescence microscopy, atomic force microscopy

\section{INTRODUCTION}

Semiconductor quantum dots have attracted a lot of attention owing to their unique properties, including a strong light emission, long fluorescent lifetime, and wavelength selection based on the quantum size effect. Single-electron transistors ${ }^{1}$, spin memories ${ }^{2)}$, and single-photon turnstile devices ${ }^{3)}$ have been fabricated using dry processes. Quantum dots fabricated using wet processes are particularly attractive for the fabrication of low-cost, low-energy quantum devices, as well as for bio-imaging ${ }^{4}$ and bio-sensing $^{5)}$ in which the quantum dots are used in water. To reduce their adverse effects on the environment, electronic and photonic devices such as sensors ${ }^{6}{ }^{6}$, Grätzel cells ${ }^{7)}$, photo memories ${ }^{8)}$, and light-emitting devices ${ }^{9}$ have been fabricated by preparing the quantum dots using a wet process.

Two-dimensional nanofabrication using top-down and bottom-up techniques has attracted a great deal of attention in recent years in various fields such as electronics and photonics. The top-down techniques used include photolithography ${ }^{10)}$, electron beam lithography ${ }^{11)}$, soft lithography ${ }^{12)}$, dip-pen nanolithography ${ }^{13)}$, and near-field optical lithography ${ }^{14)}$. However, these techniques have potential problems in that they increase the energy consumption and size of the facilities used to fabricate large nanoscale patterns on solid substrates. Although efforts have been made to decrease the patterning size using standard lithography technologies, the fabrication of nanostructured materials by bottom-up methods using self-assembling systems has been recognized as a powerful approach for establishing novel nanolithography technologies. Self-assembly allows molecules or molecular aggregates to form nanopatterns on solid substrates in the absence of external stimuli such as photo-irradiation through photomasks or scanning of the substrate surface with probes. Lopes and Jaeger characterized the electrical properties of nano-metals introduced into nanopatterned structures of phase-separated block copolymers ${ }^{15)}$.

\footnotetext{
*Correspondence to: Satoshi Watanabe, Department of Materials Science and Technology, Tokyo University of Science, Yamazaki 2641, Noda 278-8510, Japan.

E-mail: watasato@rs.noda.tus.ac.jp Accepted December 11, 2011 (recieved for review September 30, 2011) Journal of Oleo Science ISSN 1345-8957 print / ISSN 1347-3352 online http://www.jstage.jst.go.jp/browse/jos/ http://mc.manusriptcentral.com/jjocs
} 
The Langmuir-Blodgett(LB)technique has long been known as a useful method for preparing organic monolayers on solid substrates ${ }^{16,17)}$. Nanolath lattices consisting of stripes and channels with alternating wettability are fabricated using the wetting instabilities during the LB transfer $^{18)}$. Phase-separated structures are often formed in mixed LB films fabricated from two amphiphilc molecules ${ }^{19-29)}$.

We controlled the phase-separated structures in mixed LB films. The domain shape and size are governed by two competing interactions of line tension and dipole-dipole interaction $^{20,21)}$. The former favors the formation of large, disk-type domains in the mixed LB films of fatty acids and silane-coupling agents. These domains consist of fatty acids surrounded by monolayers of the silane-coupling agents. Dipole-dipole interaction favors the formation of domains at the nanometer length scale in the mixed LB films. Through adjustment of the alkyl chain length of the amphiphiles, we can control the line tension, which enables us to obtain nanowires in mixed LB films.

We patterned various materials using phase-separated mixed LB films. Disk, spiral, and nanowire domains form in mixed LB films consisting of amphiphilic carboxylic acids and silane-coupling agents ${ }^{20,24)}$, and templates can be fabricated using these mixed LB films. We have successfully patterned $\mathrm{Cu}^{25)}$, gold nanoparticles ${ }^{26)}$, organic dyes ${ }^{27)}$, silica nanoparticles $^{28)}$, titania, and zirconia films ${ }^{29)}$.

As described above, conventional nanoparticles such as gold and silica were selectively immobilized on the templates fabricated from mixed LB films using the electrostatic force between the nanoparticles capped with carboxyl groups and a monolayer of silane-coupling agents with amino groups. In this study, we examine the selective immobilization of fluorescent nanoparticles such as CdSnanoparticles (CdS-NPs) and CdSe/ZnS-NPs on templates fabricated from mixed LB films using a liquid adsorption method. We also discuss how to control the density of the immobilized-CdSe/ZnS-NPs on the templates through variations in the concentration of the aqueous dispersion CdSe/ZnS-NPs. We used atomic force microscopy (AFM), scanning electron microscopy (SEM), and fluorescence microscopy to investigate the morphology and optical properties of the semiconductor quantum-dot-immobilized templates.

\section{EXPERIMENTAL PROCEDURES}

\subsection{Materials}

The numbers following $\mathrm{F}$ and $\mathrm{H}$ are the lengths of the perfluorocarbon and hydrocarbon, respectively. "A" stands for a carboxylic group. Icosanoic acid $\mathrm{C}_{19} \mathrm{H}_{39} \mathrm{COOH}(\mathrm{H} 19 \mathrm{~A})$ was purchased from Acros Organics. Heptadecafluoro1,1,2,2-tetrahydrodecyltrichlorosilane $\mathrm{C}_{8} \mathrm{~F}_{17} \mathrm{C}_{2} \mathrm{H}_{4} \mathrm{SiCl}_{3}$ (F8H2SiCl) and heptadecafluoro-1,1,2,2-tetrahydrodecyl- trimethoxysilane $\mathrm{C}_{8} \mathrm{~F}_{17} \mathrm{C}_{2} \mathrm{H}_{4} \mathrm{Si}\left(\mathrm{OCH}_{3}\right)_{3}(\mathrm{~F} 8 \mathrm{H} 2 \mathrm{SiOMe})$ were obtained from Gelest, Inc. 3-Aminopropyltrimethoxysilane (APS) was obtained from Kanto Chemicals Co., Ltd. The hexane spreading solvent was of spectroscopic grade, and was purchased from Dojindo and Wako Pure Chemical Industries, Ltd. The compounds used in the preparation of the CdS-NPs, such as cadmium acetate dihydrate $\mathrm{Cd}$ $\left(\mathrm{OCOCH}_{3}\right)_{2} \cdot 2 \mathrm{H}_{2} \mathrm{O}$, sodium sulfide $\mathrm{Na}_{2} \mathrm{~S}$, and 3-mercaptopropionic acid $\mathrm{HS}\left(\mathrm{CH}_{2}\right)_{2} \mathrm{COOH}(\mathrm{MPA})$, were purchased from Aldrich. $1 \mathrm{mg} \mathrm{mL} \mathrm{mL}^{-1}$ of CdSe/ZnS-NPs capped with MPA in water was purchased from OptoSirius Corporation.

\subsection{Fabrication of CdS-NPs}

Cd-NPs were synthesized using a recipe described by Acar et al. ${ }^{30)} \cdot 66.6 \mathrm{mg}$ of $\mathrm{Cd}\left(\mathrm{OCOCH}_{3}\right)_{2} \cdot 2 \mathrm{H}_{2} \mathrm{O}$ was dissolved in $50 \mathrm{~mL}$ of water, and $0.056 \mathrm{~mL}$ of MPA was added to the solution. The $\mathrm{pH}$ of the solution was adjusted to 7.5 using a $0.1 \mathrm{M} \mathrm{NaOH}$ aqueous solution, and the solution was then deoxygenated with nitrogen gas. $50 \mathrm{~mL}$ of a $2.4 \mathrm{mM}$ $\mathrm{Na}_{2} \mathrm{~S}$ aqueous solution was added dropwise into the solution. The solution was allowed to stand for $30 \mathrm{~min}$ at room temperature. The CdS-NPs were purified from the excess materials through precipitation into isopropyl alcohol followed by centrifugation at $4000 \mathrm{rpm}$. The CdS-NPs were then dispersed in pure water at given concentrations.

\subsection{Fabrication of LB films}

$\mathrm{Si}$ wafers with naturally oxidized surfaces were kept in aqueous $\mathrm{NH}_{4} \mathrm{OH}$ and $\mathrm{H}_{2} \mathrm{O}_{2}$ at $98^{\circ} \mathrm{C}$ for 10 min and rinsed with water before use (Fig. 1a). The monolayer measurements were performed using a Lauda Filmwaage(FW1). Fatty acid and silane-coupling agents were dissolved in hexane at $1.0 \times 10^{-3} \mathrm{M}$. All the spreading solutions containing $\mathrm{F} 8 \mathrm{H} 2 \mathrm{SiOMe}$ or $\mathrm{F} 8 \mathrm{H} 2 \mathrm{SiCl}$ were prepared under a nitrogen atmosphere. The solutions were mixed at given molar ratios and spread throughout on pure water (electrical resistivity $>18.2 \mathrm{M} \Omega \mathrm{cm}$ ) at $20^{\circ} \mathrm{C}$. The molecules were compressed at $1.2 \times 10^{-2} \mathrm{~nm}^{2}$ molecule ${ }^{-1} \mathrm{~min}^{-1}$ after 5 min of evaporation time. The single-layer LB films were fabricated by transferring the Langmuir films using the vertical dipping method at an upward stroke of $5 \mathrm{~mm} \mathrm{~min}^{-1}$ onto the Si wafers (Fig. 1b). All the LB films were transferred at $10 \mathrm{mN} \mathrm{m}^{-1}$ onto the Si wafers to avoid the collapse of any parts of the monolayers at the air-water interface, considering that the Langmuir films of silane-coupling agents collapse at a higher surface pressure.

\subsection{Fabrication of the templates}

Mixed LB films of fatty acid and silane-coupling agents were heated at $110^{\circ} \mathrm{C}$ for $30 \mathrm{~min}$, resulting in the formation of covalent bonds between the silane-coupling agents and Si wafers. The mixed LB films were then rinsed with ethanol for the selective removal of the fatty acids (Fig. 1c). 
(a)

$$
\checkmark \begin{aligned}
& \mathrm{H} 19 \mathrm{~A} \\
& \mathrm{~F} 8 \mathrm{H} 2 \mathrm{SiX} \\
& (\mathrm{X}=\mathrm{Cl} \text { or OMe })
\end{aligned}
$$

(b)

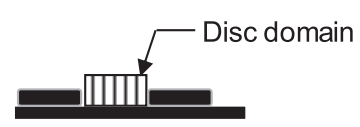

(c)

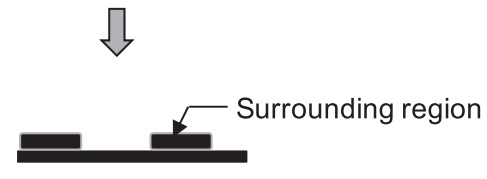

$$
\eta \text { APS }
$$

(d)

(e)
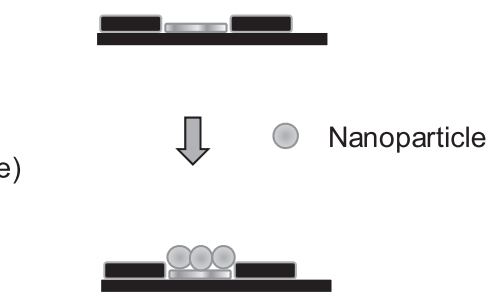

Fig. 1 Experimental scheme used for selective immobilization of quantum dots on templates. (a) Cleaning, (b) fabrication of the mixed LB film, (c) template formation, (d) template functionalization, and (e) immobilization of the quantum dots. The disk domain and surrounding region are monolayers of fatty acid and silane-coupling agents, respectively.

\subsection{Template Functionalization}

The templates were immersed in a $0.1 \mathrm{mM}$ hexane solution of APS for $4 \mathrm{~h}$ in air at room temperature to form an APS monolayer; this was done for functionalizing the exdomain regions with amino groups (Fig. 1d).

\subsection{Immobilization of quantum dots on the templates}

The amino-functionalized templates were immersed in aqueous dispersions of CdS-NPs or CdSe/ZnS-NPs at room temperature for $1 \mathrm{~h}$ to immobilize the CdS-NPs or CdSe/ ZnS-NPs in the exdomain regions with amino groups (Fig. 1e).

\subsection{Characterization}

Ultraviolet-visible (UV-Vis) absorption spectra were measured using a V-560 spectrophotometer(JASCO, Japan). Fluorescence spectra were measured using an F-4500 spectrophotometer (Hitachi, Japan). The slit widths at the excitation and emission of the spectrofluorometer are 2.5 nm. AFM observations were performed using a SPA 300 microscope controlled with a Nanonavi station(SII nanotechnology, Japan). Topographic images in tapping mode were acquired at a scan rate of $1 \mathrm{~Hz}$ using silicon nitride cantilevers with a spring constant of $15 \mathrm{~N} \mathrm{~m}^{-1}$ and a resonance frequency of $127 \mathrm{kHz}$. SEM observations were performed using an S-4200 microscope(Hitachi, Japan).

\section{RESULTS AND DISCUSSION}

3.1 Optical properties of CdS- and CdSe/ZnS-NPs in water and on the quartz plates

Over the last few decades, semiconductor quantum dots have been studied owing to their unique electrical and optical properties. The preparation of quantum dots through wet processes enables us to fabricate low-cost, low-energy quantum devices. We investigated the optical properties of CdS-NPs and CdSe/ZnS-NPs in aqueous dispersions, as well as those immobilized on quartz plates.

Figure 2(a) shows an UV-Vis absorption spectrum of an aqueous dispersion of CdS-NPs at a concentration of 4.2 $\mathrm{mg} \mathrm{mL}^{-1}$. The absorption maximum and absorption edge (a)

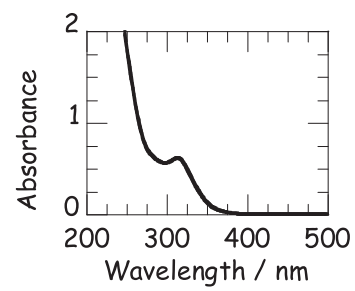

(c)

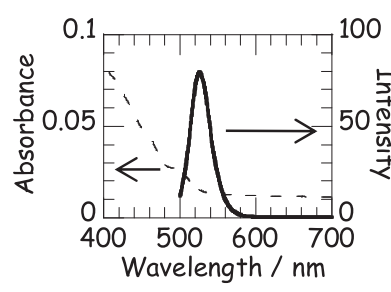

(b)

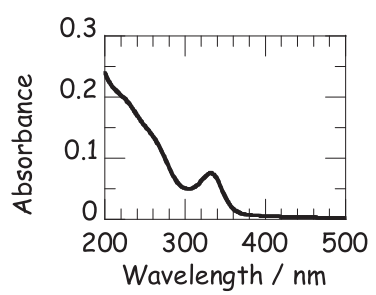

(d)

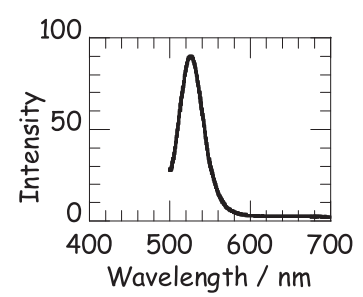

Fig. 2 (a) UV-Vis absorption spectra of CdS-NP aqueous dispersion at $4.2 \mu \mathrm{mol} \mathrm{L}{ }^{-1}$, (b) CdS-NPimmoblized quartz plate after immersion in an aqueous dispersion of CdS-NPs at $14 \mu \mathrm{mol} \mathrm{L}{ }^{-1}$, (c) UV-Vis absorption and emission spectra of an aqueous dispersion of $\mathrm{CdSe} / \mathrm{ZnS}-\mathrm{NPs}$ at 62 nmol L ${ }^{-1}$ under $440 \mathrm{~nm}$ visible light excitation (dashed and solid lines are the absorption and emission spectra, respectively), and (d) emission spectrum of the CdSe/ZnS-NP-immobilized quartz plate. 
are located at $320 \mathrm{~nm}$ and $400 \mathrm{~nm}$, respectively. The diameter of the CdS-NPs is estimated to be about $2.6 \mathrm{~nm}$ using the Brus equation ${ }^{31,32)}$. The concentration of aqueous dispersions of Cd-NPs was determined to be $4.2 \mu \mathrm{mol} \mathrm{L}{ }^{-1}$ using the molar adsorption coefficient reported by William et $a l{ }^{33)}$. Figure 2(b) shows an UV-Vis absorption spectrum of CdS-NPs immobilized on a quartz plate functionalized using the self-assembled monolayers (SAM) of APS. The absorption maximum and absorption edge were situated at almost the same wavelengths with those of the CdS-NP dispersions. These results indicate that CdS-NPs were immobilized on the quartz plates. The CdS-NPs were immobilized on the SAMs of APS owing to the electrostatic force between the carboxylic and amino groups ${ }^{26)}$. Figure 2 (c) shows UV-Vis absorption and fluorescence spectra of the aqueous dispersions of CdSe/ZnS-NPs. The absorption maximum and absorption edge appear at 500 and $530 \mathrm{~nm}$, respectively. In a report by Dabbousi et al., the diameter of the CdSe/ZnS-NPs was estimated to be about $4.5 \mathrm{~nm}^{31,34)}$. The concentration of aqueous dispersions of CdSe/ZnS-NPs was determined to be $62 \mathrm{nmol} \mathrm{L}{ }^{-1}$ using the molar adsorption coefficient reported by William et al. ${ }^{33)}$. The maximum wavelength and full width at half maximum of the fluorescence band are $530 \mathrm{~nm}$ and $30 \mathrm{~nm}$, respectively. Figure 2 (d) shows a fluorescence spectrum of the CdSe/ZnS-NPs immobilized on a quartz plate functionalized with a monolayer of APS. The maximum wavelength and full width at half maximum of the fluorescence band are almost coincident with those of the CdSe/ZnS-NP aqueous dispersions. These results indicate that the CdSe/ZnS-NPs are immobilized on the quartz plates.

\subsection{Immobilization of CdS-NPs on the templates fabri- cated from mixed LB films}

Lithography techniques using self-assembling systems have attracted a great deal of attention in establishing novel nanofabrication technologies without external stimuli such as photo-irradiation through photomasks or scanning a substrate surface using probes. We fabricated films consisting of functional materials such as copper ${ }^{25)}$, gold$\mathrm{NPs}^{26)}$, organic dye $\mathrm{e}^{27)}$, silica-NPs ${ }^{28)}$, titania, and zirconia films ${ }^{29)}$ on templates fabricated from mixed LB films ${ }^{20,24)}$ We then performed a selective immobilization of the semiconductor quantum dots of CdS-NPs on these templates using a liquid phase adsorption technique.

Figure 3(a) shows an AFM image of a mixed LB film of H19A/F8H2SiOMe $=3 / 7$. Disk domains at a diameter of several micrometers and with a relative height of $1 \mathrm{~nm}$ were formed in the mixed LB films, indicating that H19A forms these disk domains surrounded by the monolayer of F8H2SiOMe. Figure 3(b) shows an AFM image of a template fabricated from the mixed LB film described above. The height of the disk domains is smaller than the height of the surrounding regions by $1 \mathrm{~nm}$. The surface of the $\mathrm{Si}$
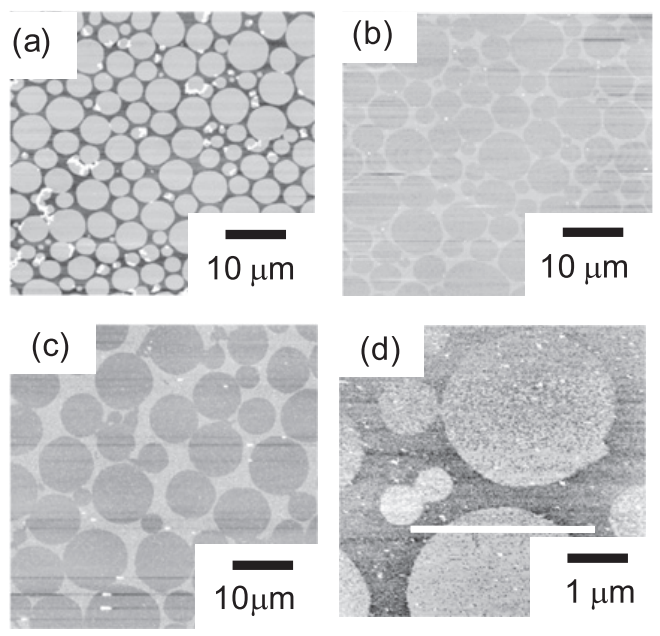

(e)

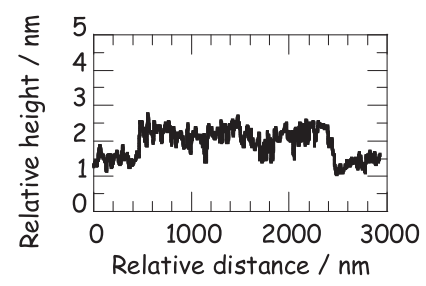

Fig. 3 (a) AFM image of mixed LB film of H19A/ $\mathrm{F} 8 \mathrm{H} 2 \mathrm{SiOMe}=3 / 7$, (b) AFM image of the template fabricated from the mixed LB film, (c) AFM image of the APS-modified template, (d) AFM image, and (e) a cross-sectional view of the CdS-NPs-immobilized template fabricated through immersion in an aqueous dispersion of CdS-NPs at $4.2 \mathrm{nmol} \mathrm{L}^{-1}$ for $10 \mathrm{~min}$.

wafer is exposed in the disk domain regions due to the se-

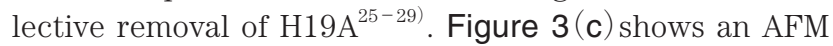
image of the APS-modified template. The height of the disk domains is smaller than the height of the surrounding regions by $0.5 \mathrm{~nm}$, indicating the formation of a monolayer of APS in the disk domain regions ${ }^{25,26)}$. Sections (d) and (e) in Fig. 3 show an AFM image and cross-sectional view of a CdS-NPs-immobilized template fabricated through immersion in the aqueous dispersion of CdS-NPs at $4.2 \mathrm{nmol} \mathrm{L}^{-1}$ for $10 \mathrm{~min}$. The height of the disk domains is higher than the height of the surrounding regions by $1 \mathrm{~nm}$. This increase in height is almost in agreement with the diameter of the CdS-NPs. These results indicate that the CdS-NPs are selectively immobilized on the APS-functionalized templates.

The adsorption of gold nanoparticles and semiconductor quantum dots capped with carboxyl groups on the solid substrates functionalized with the amino group has been analyzed based on the Langmuir adsorption model ${ }^{31,35)}$. The adsorbed nanoparticles on the substrates become saturated within around 10 to $30 \mathrm{~min}$. We also studied the im- 
mobilization of CdS-NPs on the templates for longer immersion times.

Figure 4 shows the AFM images of the CdS-NP-immobilized templates fabricated by immersion in an aqueous dispersion of CdS-NPs at $4.2 \mathrm{nmol} \mathrm{L}^{-1}$ for both (a) $1 \mathrm{~h}$ and (b) $18 \mathrm{~h}$. The Cd-NPs are immobilized in the disk domain regions. The amount of CdS-NPs immobilized in the surrounding regions of the templates increased with the immersion time. After an immersion of $24 \mathrm{~h}$, the disk domains were not recognizable on the templates, indicating the immobilization of the CdS-NPs in both the disk domain and surrounding regions. This may be due to the physical adsorption of the CdS-NPs in the surrounding regions and/or the immobilization of APS at the defects of these regions. These results indicate that the immersion time is an important factor for the selective immobilization of CdS-NPs on the templates. These results also suggest the difference between adsorption rates of the CdS-NPs in the disk domains and the surrounding regions.

\subsection{Immobilization of CdSe/ZnS-NPs on templates fabri- cated from mixed LB films}

Core-shell quantum dots have attracted a large amount of interest in electronics, photonics, and biological fields owing to their electronic and photonic properties based on the quantum size effect. We carried out the immobilization of CdS-NPs capped with a carboxylic group on the templates fabricated from the mixed LB films, as shown in Fig. 3. We also studied the immobilization of the core-shell quantum dots of the CdSe/ZnS-NPs on these templates.

Figure 5 shows normal and magnified AFM images as well as a cross-sectional view of the CdSe/ZnS-NP-immobilized template fabricated from a mixed LB film of H17A/ $\mathrm{F} 8 \mathrm{H} 2 \mathrm{SiCl}=1 / 9$. The concentration of the aqueous dispersion of CdSe/ZnS-NPs and the immersion time were 6.3 nmol $\mathrm{L}^{-1}$ and $1 \mathrm{~h}$, respectively. The height of the disk domains is larger than the height of the surrounding regions by $5 \mathrm{~nm}$. The density of the immobilized CdSe/
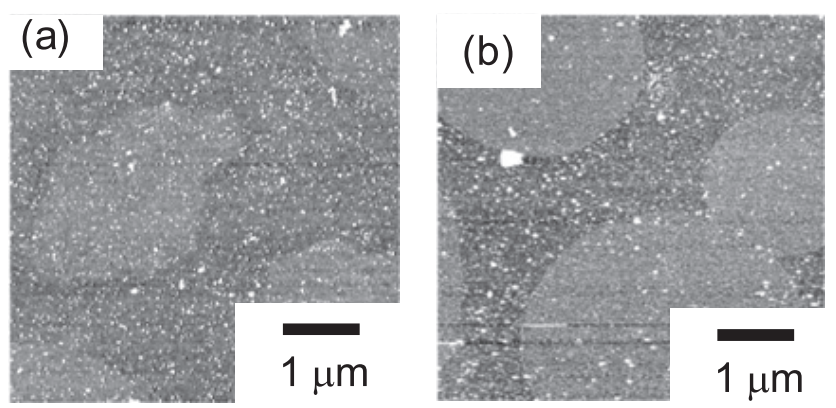

Fig. 4 AFM images of CdS-NPs-immobilized templates fabricated from mixed LB films of H19A/ $\mathrm{F} 8 \mathrm{H} 2 \mathrm{SiOMe}=3 / 7$, followed by immersion in an aqueous dispersion of CdS-NPs at a concentration of $4.2 \mathrm{nmol} \mathrm{L}^{-1}$ for (a) $1 \mathrm{~h}$ and (b) $18 \mathrm{~h}$.
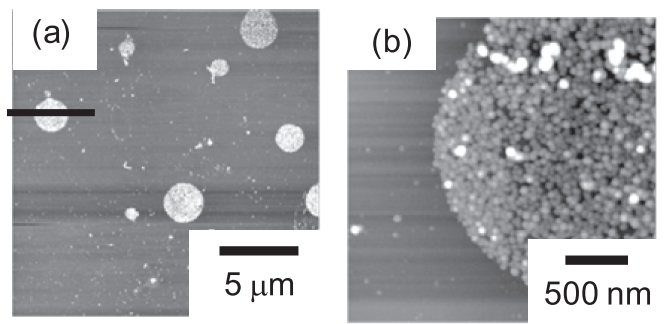

(c)

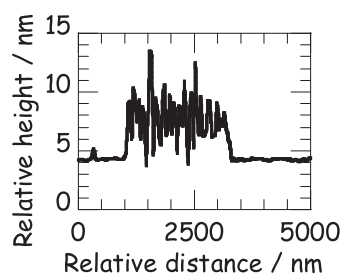

Fig. 5 (a) Normal and (b) magnified AFM images and (c) a cross-sectional view of a CdSe/ZnS-NPsimmobilized template fabricated from a mixed $\mathrm{LB}$ film of $\mathrm{H} 19 \mathrm{~A} / \mathrm{F} 8 \mathrm{H} 2 \mathrm{SiCl}=1 / 9$. The concentration of the aqueous dispersion of $\mathrm{CdSe} / \mathrm{ZnS}$ NPs was $6.25 \mathrm{nmol} \mathrm{L}^{-1}$.

ZnS-NPs in the disk domain regions is estimated to be about $1.0 \times 10^{11} \mathrm{~cm}^{-2}$ when counting the number of CdSe/ ZnS-NPs in the AFM images. The surface coverage of the CdSe/ZnS-NPs is estimated to be about 2.0\%, assuming that the diameter of the CdSe/ZnS-NPs is equal to their height. This value nearly coincides with that of CdSe/ ZnS-NPs adsorbed on substrates reported by Park et $a l^{31)}$. These results indicate the selective immobilization of CdSe/ZnS-NPs on the templates.

Figure $6(\mathrm{a})$ shows normal and magnified AFM images of a CdSe/ZnS-NP-immobilized template fabricated through immersion in an aqueous dispersion of CdSe/ZnS-NPs at $3.2 \mathrm{nmol} \mathrm{L}^{-1}$ for $1 \mathrm{~h}$. The CdSe/ZnS-NPs are immobilized in the disk domain regions at a density of $7.1 \times 10^{10} \mathrm{~cm}^{-2}$. The surface coverage of the CdSe/ZnS-NPs is about $1.4 \%$. Figure 6 (b) shows normal and magnified AFM images of the CdSe/ZnS-NP-immobilized template fabricated through immersion in an aqueous dispersion of CdSe/ZnS-NPs at $0.6 \mathrm{nmol} \mathrm{L}^{-1}$ for $1 \mathrm{~h}$. The CdSe/ZnS-NPs are immobilized in the disk domain regions at a density of $1.5 \times 10^{10} \mathrm{~cm}^{-2}$. The surface coverage of the CdSe/ZnS-NPs is about $0.3 \%$. These results indicate that the density of the immobilizedCdSe/ZnS-NPs on the templates can be controlled through variations in the concentration of their aqueous dispersion.

Figure 7 (a) shows normal and magnified SEM images of the CdSe/ZnS-NPs-immobilized template. As in the AFM images (Fig. 5), disk domains with a diameter of several micrometers are present. The emission of secondary electrons from the disk domain regions is higher than that from the surrounding regions due to the immobilization of the 
(a)
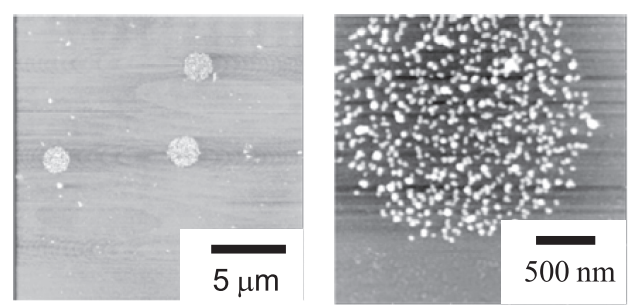

(b)
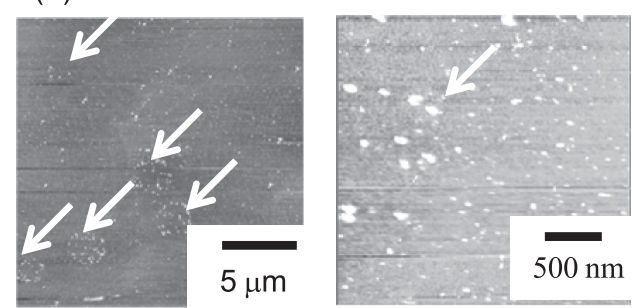

Fig. 6 Normal and magnified AFM images of CdSe/ ZnS-NPs-immobilized templates fabricated from mixed LB films of $\mathrm{H} 19 \mathrm{~A} / \mathrm{F} 8 \mathrm{H} 2 \mathrm{SiCl}=1 / 9$. The concentrations of the aqueous dispersions of CdSe/ZnS-NPs were (a) $3.2 \mathrm{nmol} \mathrm{L}^{-1}$ and (b) $0.625 \mathrm{nmol} \mathrm{L}^{-1}$.
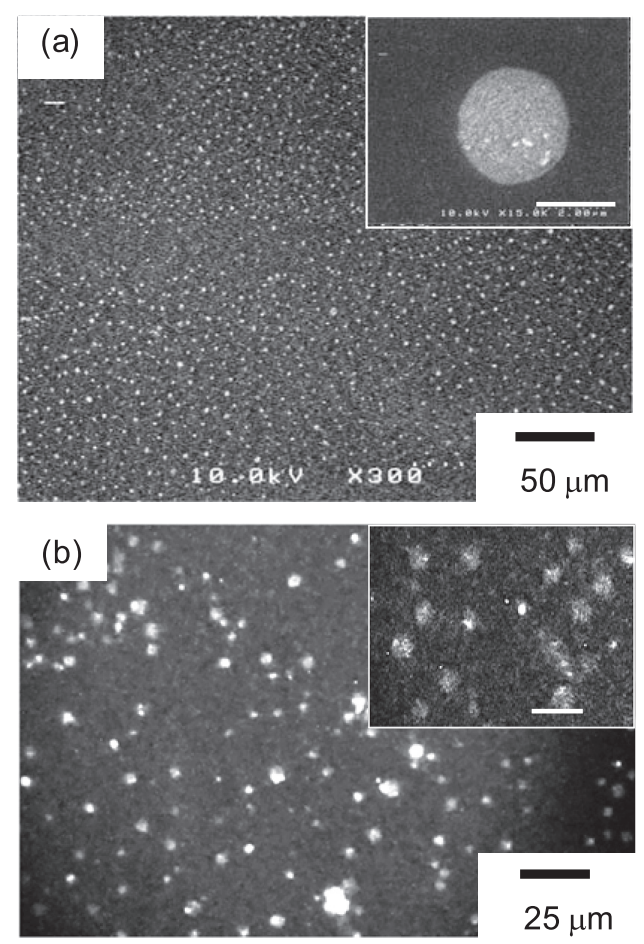

Fig. 7 (a) SEM and (b) fluorescence images at $550 \mathrm{~nm}$ of $\mathrm{CdSe} / \mathrm{ZnS}$-immoblized template fabricated from a mixed $\mathrm{LB}$ film of $\mathrm{H} 19 \mathrm{~A} / \mathrm{F} 8 \mathrm{H} 2 \mathrm{SiCl}=1 / 9$. The white scale bars in the inset images of (a) and (b) are $2 \mu \mathrm{m}$ and $10 \mu \mathrm{m}$, respectively.
CdSe/ZnS-NPs. Figure $7(\mathbf{b})$ shows normal and magnified fluorescence images of the CdSe/ZnS-NPs-immobilized template. Bright spots due to green fluorescence from the CdSe/ZnS-NPs are evident. The size of the bright spots is similar to that of the disk domains shown in the AFM and SEM images (Fig. 5 and Fig. 7a, respectively). These results indicate that the immobilized-CdSe/ZnS-NPs on the templates serve as light-emitting devices.

\section{CONCLUSION}

We patterned functional materials on templates fabricated from phase-separated mixed LB films using only self-assembly processes ${ }^{25-29)}$. The phase-separated structures can be tuned by adjusting the intermolecular interactions between the film-forming molecules ${ }^{20,211}$. In this study, two types of semiconductor quantum dots were immobilized on the templates. AFM observations reveal the formation of patterned single layers consisting of semiconductor quantum dots on the templates, and that the density of these semiconductor quantum dots can be controlled by altering the experimental conditions. Fluorescence microscopy shows that a green fluorescence is emitted from the patterned regions immobilized with the quantum dots, indicating that these semiconductor quantum dots serve as light-emitting devices on the templates.

It is particularly interesting to note that unique phaseseparated structures such as spirals, hexagons, and nanowires can be formed in mixed LB films consisting of fatty acids, hybrid carboxylic acids, and silane coupling agents by adjusting the intermolecular interactions between the film-forming molecules ${ }^{20)}$. This provides a means to controlling the size and shape of the domains in the templates for the patterning of semiconductor quantum dots. The present methodology enables us to fabricate quantum dots on templates with chemically patterned surfaces formed through self-assembling systems and has potential applications in the two-dimensional nanofabrication of various functional materials for low-cost, high-throughput high-density memory, light-emitting devices, and sensors.

\section{Acknowledgment}

This work was partly supported by the Japan Society for the Promotion of Science (Grant No. 22850017).

\section{Reference}

1) Goldhaber-Gordon, D.; Shtrikman, H.; Mahalu, D.; Abusch-Magder, D.; Meirav, U.; Kastner, M. A. Nature, 
391156 (1998).

2) Kroutvar, M.; Ducommun, Y.; Heiss, D.; Bichler, M.; Schuh, D.; Abstreiter, G.; Finley, J. J. Nature, 43281 (2004).

3) Michler, P.; Kiraz, A.; Becher, C.; Schoenfeld, W. V.; Petroff, P. M.; Zhang, L.; Hu, E.; Imamogùlu, A. Science, 2902282 (2000).

4) Medintz, I. L.; Uyeda, H. T.; Goldman, E. R.; Mattoussi, H. M. Nature Mater., 4436 (2005).

5) Chan, W. C. W.; Nie, S. Science, 2812016 (1998).

6) Goldman, E. R.; Medintz, I. L.; Whitley, J. L.; Hayhurst, A.; Clapp, A. R.; Uyeda, H. T.; Deschamps, J. R.; Lassman, M. E.; Mattoussi, H. J. Am. Chem. Soc., 127 6744(2005).

7) Robel, I.; Subramanian, V.; Kuno, M.; Kamat, P. V. J. Am. Chem. Soc., 128 2385(2006)

8) Maenosono, S.; Ozaki, E.; Yoshie, K.; Yamaguchi, Y. Jpn. J. Appl. Phys., 40 L638(2001).

9) Rizzo, A.; Mazzeo, M.; Palumbo, M.; Lerario, G.; Amone, S. D.; Cingolani, R.; Gigli, G. Adv. Mater., 20 1886 (2008).

10) Horiuchi, S.; Fujita, T.; Hayakawa, T.; Nakao, Y. Adv. Mater., 151449 (2003).

11) Myers B. D.; Dravid C. P. Nano Lett., 66963 (2006).

12) Kumar, A.; Biebuyck, H. A.; Whitesides, G. M. Langmuir, 10 1498(1994).

13) Piner, R. D.; Zhu, J.; Xu, F.; Hong, S.; Mirkin, C. A. Science, 283661 (1999).

14) Krämer, S.; Fuierer, R. R.; Gorman, C. B. Chem. Rev., 1034367 (2003).

15) Lopes, W. A.; Jaeger, H. M. Nature, 414735 (2001).

16) Ulman, A. An Introduction to ULTRATHIN ORGANIC FILMS From Langmuir-Blodgett to Self-Assembly, Academic Press, Boston(1991).

17) Roberts, G. Langmuir-Blodgett Films, Plenum Press, New York (1990).

18) Gleiche, M.; Chi, L. F.; Fuchs, H. Nature, 403173 (2000).

19) Iimura, K.; Shiraku, T.; Kato, T. Langmuir, 1810183 (2002).

20) Matsumoto, M.; Watanabe, S.; Tanaka, K.; Kimura, H.;
Kasahara, M.; Shibata, H.; Azumi, R.; Sakai, H.; Abe, M.; Kondo, Y.; Yoshino, N. Adv. Mater., 193668 (2007).

21) Kimura, H.; Watanabe, S.; Shibata, H.; Azumi, R.; Sakai, H.; Abe, M.; Matsumoto, M. J. Phys. Chem. B, $11215313(2008)$.

22) Ge, S.; Takahara, A.; Kajiyama, T. Langmuir, 111341 (1995).

23) Matsumoto, M.; Tanaka, K.; Azumi, R.; Kondo, Y.; Yoshino, N. Langmuir, 208728 (2004)

24) Mazaki, T.; Shibata, H.; Kondo, Y.; Yoshino, N.; Matsumoto, M. Chem. Lett., 37480 (2008).

25) Watanabe, S.; Kimura, H.; Sato, T.; Shibata, H.; Sakamoto, F.; Azumi, R.; Sakai, H.; Abe, M.; Matsumoto, M. Langmuir, 24 8735(2008).

26) Watanabe, S.; Shibata, H.; Sakamoto, F.; Azumi, R.; Sakai, H.; Abe, M.; Matsumoto, M. J. Mater. Chem., 19 6796 (2009).

27) Watanabe, S.; Shibata, H.; Horiuchi, S.; Azumi, R.; Sakai, H.; Abe, M.; Matsumoto, M. J. Colloid Interface Sci., 343324 (2010)

28) Shibata, H.; Sato, M.; Watanabe, S.; Matsumoto, M. Colloid Surface A: Physicochem. Eng. Aspects, 346 58(2009).

29) Sato, M.; Shibata, H.; Sakai, H.; Abe, M.; Matsumoto, M. Trans. Mater. Res. Soc. Jpn., 33111 (2008).

30) Acar, H. Y.; Kas, R.; Yurtsever, E.; Ozen, C.; Lieberwirth, I. J. Phys. Chem. C, 11310005 (2009).

31) Park, J. J.; Lacerda, S. H. D. P.; Stanley, S. K.; Vogel, B. M.; Kim, S.; Douglas, J. F.; Raghavan, D.; Karim, A. Langmuir, 25 443(2009).

32) Murray, C. B.; Noms, D. J.; Bawendi, M. G. J. Am. Chem. Soc., 1158706 (1993).

33) William, W. Y.; Qu, L.; Guo, W.; Peng, X. Chem. Mater., $152854(2003)$.

34) Dabbousi, B. O.; Rodriguez-Viejo, J.; Mikulec, F. V.; Heine, J. R.; Mattoussi, H.; Ober, R.; Jensen, K. F.; Bawendi, M. G. J. Phys. Chem. B, 1019463 (1997).

35) Enders, D.; Nagao, T.; Nakayama, T.; Aono, M. Langmuir, 236119 (2007). 